\title{
Happy birthday Heinz Falk
}

\author{
Peter Gärtner ${ }^{1}\left[\right.$ Mario Waser $^{2}$
}

Received: 19 April 2019 / Accepted: 20 April 2019 / Published online: 29 April 2019

(c) Springer-Verlag GmbH Austria, part of Springer Nature 2019

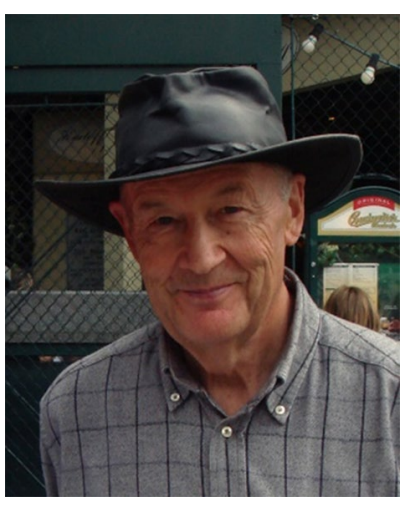

Dear readers,

This special issue of Chemical Monthly is dedicated to Professor Heinz Falk, on the occasion of his 80th birthday. As most of the readers know, Prof. Falk was editor and the editor-in-chief for about 18 years until 2009 who shaped the journal and had a lasting influence on its development over a very long period. Therefore, he will definitely not need much introduction to the readership of Chemical Monthly, as the majority will be very much aware of his longstanding contributions not only to our journal, but also to the (Austrian) chemical society in general. Prof. Falk has been one of the leading (physical) organic chemists in Austria for the last five decades, whose contributions to the fields of synthetic chemistry, stereochemistry, photochemistry, and natural product chemistry have had a significant impact

Peter Gärtner

peter.gaertner@tuwien.ac.at

$\triangle$ Mario Waser

mario.waser@jku.at

1 Institute of Applied Synthetic Chemistry, TU Wien, Getreidemarkt 9, 1060 Vienna, Austria

2 Institute of Organic Chemistry, Johannes Kepler University Linz, Altenbergerstraße 69, 4040 Linz, Austria on the organic chemistry community. He was born in St. Pölten, Austria on April 29, 1939 and studied chemistry at the University of Vienna, where he obtained his PhD under the supervision of the late Prof. Karl Schlögl in 1966, working on the configuration of optically active ferrocene derivatives. He then started his independent career in Vienna and obtained his habilitation for organic chemistry in 1972. During his habilitation, he carried out investigations on the stereochemistry of chiral metallocenes. During this period, he also carried out postdoctoral research in the group of Prof. Albert Eschenmoser at the ETH Zürich (1971). In 1975, Prof. Falk was promoted to become an Assoc. Prof. for physical organic chemistry at the University of Vienna and in 1979 he accepted a call from the Johannes Kepler University of Linz (JKU), to found the new Institute of Organic Chemistry, which he chaired until his retirement as a Professor emeritus in 2008. During this time, he became well renowned for his seminal contributions on photosensitizing and photosensory pigments. He carried out fundamental studies concerning the synthesis, stereochemistry and photochemistry of bile pigments first and later in his career his major research interest was on the chemistry of natural phenanthroperylene-based pigments like hypericin or stentorin. Besides this, he always had very strong and fruitful collaborations with the chemical industries and over his whole career he has published more than 300 papers and 2 books and supervised nearly one hundred doctoral students and post docs.

His research contributions were recognized by several prestigious awards, like the Ernst Späth Prize of the Austrian Academy of Sciences in 1976, the Sandoz Prize in 1977 or the Josef Loschmidt Medal of the Austrian Chemical Society in 1998. In 1997, he was also elected as a full member to the Austrian Academy of Sciences and in 2003 he was elected as a member of the European Academy of Sciences.

All these achievements and awards and recognitions clearly show that Prof. Heinz Falk not only focused on his own research, but he also carried out several important official functions at universities (e.g. he was Dean of the Faculty of Engineering and Natural Sciences at JKU from 
1989-91), the Austrian Chemical Society (here he was vice president for several years), and scientific journals (besides his already mentioned time as an editor in chief for Chemical Monthly, he has also served as a series editor for Progress in the Chemistry of Organic Natural Products, Springer, since 1998).

Besides his broad chemistry-related interests, Prof. Falk was always very passionate for science and art in general. He is a well-recognized mineralogist, studied egyptology, and loves going to the opera or theater. All these passions have always been shared by his wife Rotraud, who he married in 1966 (having one son, Alexander Falk) and who supported him throughout his whole career.

The two of us have had the great privilege to know Prof. Heinz Falk for years now and we can wholeheartedly say that over all these years he has not only been an inspiring scientist and mentor to us, but also a wonderful colleague and friend, who had an everlasting impact on our own careers. Therefore, it is really our big pleasure that now, on the occasion of his 80th birthday, so many of his former students, co-workers, colleagues and especially friends agreed to contributed to this special issue. As you will see throughout the whole issue, the covered topics are as broad and diverse as Prof. Falk's research interests and hobbies have been throughout his career. You will find contributions in the field of organic synthesis besides more analytical or physical chemistry related ones. We have also received personal contributions and articles from the chemical industry and we are also very grateful to contributions that are more mineralogy related.

A very special part at the end of this issue reports on chemistry history. The first topic focuses on Ernst Späth's synthesis of mescaline which was published in Monatshefte für Chemie/Chemical Monthly 100 years ago and in three papers it is outlined how mescaline was discovered and what was the influence of Ernst Späth's work on further developments in this area. Heinz Falk can be seen from a chemical point of view as grandson of Späth and he is also as mentioned above recipient of the Ernst Späth Prize. Heinz Falk as Ernst Späth are and were both very much interested in the chemistry of natural products.

The last paper then describes the history of female chemistry students at the University of Vienna at that time which is very interesting not only but also because they were only allowed to study there since 1897 and their scientific contribution in Monatshefte für Chemie/Chemical Monthly are discussed.

Altogether you will find a very exciting collection of articles in honor of Prof. Falk and we wish to thank all the authors for their excellent contributions. We hope that all of you will enjoy reading these articles and want to close this editorial with a very warm "Happy Birthday Heinz, ad multos annos".

Sincerely, Peter and Mario.

Publisher's Note Springer Nature remains neutral with regard to jurisdictional claims in published maps and institutional affiliations. 